Original Research Paper

\title{
Role of Clothing Insulation for Thermal Comfort: A Numerical Study using Bio-Heat Transfer Model
}

\author{
${ }^{1}$ Kabita Luitel, ${ }^{2}$ Dil Bahadur Gurung, ${ }^{3}$ Harihar Khanal and ${ }^{4}$ Kedar Nath Uprety \\ ${ }^{1}$ Department of Mathematics, Bhaktapur Multiple Campus, Nepal \\ ${ }^{2}$ Department of Mathematics, Kathmandu University, Kavre, Dhulikhel, Nepal \\ ${ }^{3}$ Department of Mathematics, Embry-Riddle Aeronautical University, Daytona Beach, Florida, USA \\ ${ }^{4}$ Central Department of Mathematics, Tribhuvan University, Kirtipur, Nepal
}

\author{
Article history \\ Received: 18-09-2020 \\ Revised: 21-12-2020 \\ Accepted: 23-12-2020 \\ Corresponding Author: \\ Kabita Luitel \\ Department of Mathematics, \\ Bhaktapur Multiple Campus, \\ Nepal \\ Email: kabi123luitel@gmail.com
}

\begin{abstract}
Clothing plays a major role in protecting the human body from cold and hot environment by working as an insulator. The physical factors such as conduction, convection, radiation, evaporation and the physiological factors such as blood flow and metabolism within the body together with clothing system help to maintain human thermal comfort and the human thermoregulatory system. On the other hand, body is continuously losing a small amount of heat from the air gap between skin surface and protective clothes. This paper studies the role and effect of the insulations of clothes and air for dry heat loss and the moisture transfer due to air velocity along with walking speed and observes how they work together for temperature distribution in human body. Pennes' bioheat equation is taken as a model and Backward in Time and Central in Space (BTCS) scheme is used for obtaining the solution of the model. Clothing parameters, wind speed and walking speed have been added in the boundary condition in Pennes's model among them the clothing insulation helps prevent the heat loss whereas air velocity escalate heat loss from the body. The numerical results are implemented in Python.
\end{abstract}

Keywords: Thermal Comfort, Thermoregulatory System, Bioheat Transfer, Clothing and Air Insulation, Air Velocity

\section{Introduction}

Human's thermal comfort is not only the state of mind for satisfaction with environmental condition, but also balancing the body's core temperature $37^{\circ} \mathrm{C}$ (within the range $\pm 0.6^{\circ} \mathrm{C}$.) and thermoregulatory system. Body's internal physical and physiological phenomena such as conduction, convection, radiation, sweat evaporation, blood flow and metabolism in addition with the insulation of clothes and air and clothing area factors are the key thermal properties for balancing the uniform body temperature (Hall and Hall, 2020; Özişik et al., 2017; Luitel et al., 2018). These important components of the heat balance under the transient condition, the thermal energy generated by metabolism or transferred from solar radiation to the body part may go to alter the amount storage inside it.

Thermal comfort is one of the physiological concepts that effects by the human personal and environmental factors. Metabolism and clothes are the personal factors, if they change in little amount, the person's thermal comfort also changes. Radiant temperature, air temperature, long-wave radiation and radiation exchange with environment and short-wave absorption of solar radiation, on the other hand, can be categorized as the environmental factors (Holmér, 1995).

Human body continuously produces heat through metabolism, which is the rate of energy with time, therefore, has unit Watt(W). During the estimation of metabolic heat production rate of a specific activity, the value is generally related to the body volume (Pennes, 1948). So, the unit $W / \mathrm{m}^{3}$ is used for the metabolic heat generation in the internal body temperature in bioheat transfer equations whereas (Voelker et al., 2009; Havenith et al., 2002; Holmér, 1995; Oğulata, 2007) used this metabolic heat generation rate in $W / \mathrm{m}^{2}$ in relation with body surface area. MET is sometimes used for metabolic rate where the metabolic rate of seated person is given by:

$$
1 M E T=50 \mathrm{kcal} / \mathrm{m} \cdot \mathrm{h}=58.2 \mathrm{~W} / \mathrm{m}
$$


Body temperature may fall or rise according to the changes in external environment, internal physical and physiological parameters. Persons can minimize and keep the temperature balance by engaging themselves in exercise and using the comfort clothes during cold and sweating during hot environment (Havenith, 1999).

The heat exchange between human and surrounding can be written in the heat balance equation per unit body surface area as (Havenith, 1999; Luitel et al., 2019; Oğulata, 2007):

$M-W_{e}=C+R+E_{s}+\left(C_{r}+E_{r}\right)+C_{k}$

\section{Nomenclature}

$A_{b} \quad$ Surface area of nude body $\left(\mathrm{m}^{2}\right)$

$A_{c l} \quad$ Surface area of clothed body $\left(\mathrm{m}^{2}\right)$

$C \quad$ Heat loss through convection $\left(\mathrm{W} / \mathrm{m}^{2}\right)$

c Tissue specific heat $\left(\mathrm{j} / \mathrm{kg}^{\circ} \mathrm{C}\right)$

$c_{b} \quad$ Blood specific heat $\left(j / k^{\circ} \mathrm{C}\right)$

$C_{k} \quad$ Heat loss through thermal conduction $\left(\mathrm{W} / \mathrm{m}^{2}\right)$

$c_{r} \quad$ heat loss through respiration $\left(\mathrm{W} / \mathrm{m}^{2}\right)$

$E_{a} \quad$ Heat loss through evaporation $\left(W / m^{2}\right)$

$E_{r} \quad$ Respiratory evaporative heat loss $\left(\mathrm{W} / \mathrm{m}^{2}\right)$

$F_{c l} \quad$ Clothing efficiency factor (dimensionless)

$f_{c l} \quad$ Clothing area factor (dimensionless)

$h_{A} \quad$ Combined heat transfer coefficient $\left(\mathrm{W} / \mathrm{m}^{2} .{ }^{\circ} \mathrm{C}\right)$

$h_{c} \quad$ Convective heat transfer coefficient $\left(W / m^{2} .{ }^{\circ} \mathrm{C}\right)$

$I_{a} \quad$ Insulation of air $\left(\mathrm{m}^{2} .{ }^{\circ} \mathrm{C} / \mathrm{W}\right)$

$I_{c l} \quad$ Insulation of clothes $\left(\mathrm{m}^{2} .{ }^{\circ} \mathrm{C} / \mathrm{W}\right)$

$k \quad$ Thermal conductivity of body $\left(W / m .{ }^{\circ} \mathrm{C}\right)$

$q_{m} \quad$ Metabolic heat generation $\left(\mathrm{W} / \mathrm{m}^{3}\right)$

$r \quad$ Radial distance $(m)$

$\rho \quad$ Tissue density $\left(W / m^{2}\right)$

$T_{a} \quad$ Arterial temperature $\left({ }^{\circ} \mathrm{C}\right)$

$T \quad$ Tissue (body) temperature $\left({ }^{\circ} \mathrm{C}\right)$

$T_{\infty} \quad$ Surrounding temperature $\left({ }^{\circ} \mathrm{C}\right)$

$v_{a} \quad$ Velocity of air $(\mathrm{m} / \mathrm{s})$

$v_{\text {air }}$ Relative air velocity $(\mathrm{m} / \mathrm{s})$

$W_{b} \quad$ Relative air velocity $\left(\mathrm{kg} / \mathrm{m}^{3}\right)$

$W_{e} \quad$ External work $(W)$

$W_{s} \quad$ Walking speed $(\mathrm{m} / \mathrm{s})$

\section{Heat Transfer at the Skin Surface Due to Clothing}

The skin releases the amount of latent heat which is caused either by the hot climatic condition or by the high physical exercise and secondly, the human body's evaporation is limited to the surrounding vapor pressure (Voelker et al., 2009; Parsons, 1988). Thirdly, fabric structure having different level of porosity, has different amount of entrapped air in the fabric. Tightly woven fabric having less permeability to air prevents heat loss.

\section{Thermal Insulation of Clothes}

The thermal resistance and the insulation provided by any layer of trapped air and the insulation value of clothes whose measurement is generally taken in Clo unit. The standard measurement of insulation in ASHARE Standard 55, ISO 7730 and ISO-9920 (Havenith et al., 2015) measured the clothing surface area and insulation which is based on the photographic method on the cylindrical limb of manikin. Some of these experimentally finding values of insulation for the non-western ensembles, are used in this study. The thermal resistance and the insulation provided by any layer of trapped air and the insulation value of clothes whose measurement is generally taken in Clo unit.

$1 \mathrm{Clo}$ is defined as the insulation of clothing system that requires to a comfortably sitting-resting average male in a normally ventilated room. It is the thermal insulation of overall clothing worn by the person not only the particular garment in $0.1 \mathrm{~m} / \mathrm{s}$ air velocity at air temperature $21^{\circ} \mathrm{C}$ and relative humidity less than $50 \%$. Among the total heat produced by metabolic reaction, $24 \%$ heat is lost through evaporation and respiration. The limbs of human body with insulation parameters can be seen in Fig. 1.

\section{Clothing Efficiency Factor and the Convective Heat Transfer Coefficient}

The ratio of clothed human body surface area $A_{c l}$ and nude body surface area $A_{b}$ is defined as the clothing area factor. The average body surface area of man is nearly $1.8 \mathrm{~m}^{2}$. ISO-9920 (Voelker et al., 2009; Havenith et al., 2015) have calculated this factor $f_{c l}$ as:

$$
f_{c l}=\frac{A_{c l}}{A_{b}}
$$

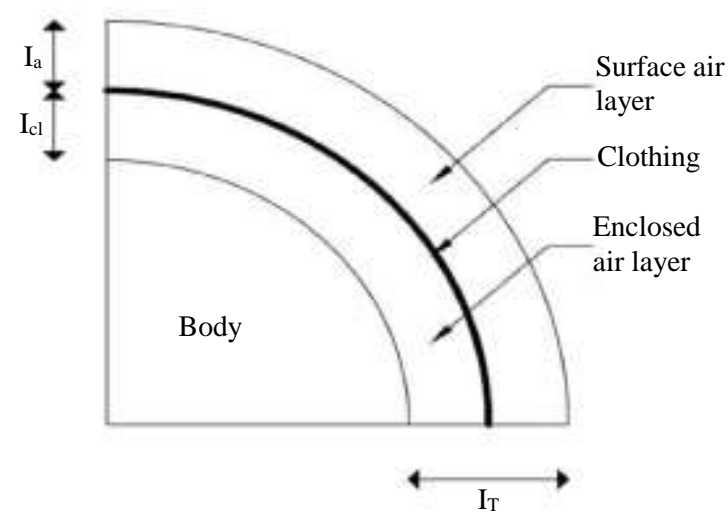

Fig. 1: Circular limb with clothing and air insulation (Havenith et al., 2015) 
The equation for this $f_{c l}$ in ISO-9922 is calculated as the function of clothing insulation $I_{c l}$ in Clo value and given by:

$$
f_{c l}=1+0.31 I_{c l}
$$

As 1 Clo $=0.155 \mathrm{~m}^{2} .{ }^{\circ} \mathrm{C} / \mathrm{W}$, the same equation becomes:

$$
f_{c l}=1+1.97 I_{c l}
$$

ASHARE standard 55 (Havenith et al., 2015) prescribes the clothing efficiency factor without air velocity is given as:

$$
F_{c l}=\frac{I_{a}}{I_{T}}=\frac{I_{a}}{I_{c l}+I_{a} / f_{c l}}
$$

The total insulation of clothing and air $I_{T}=I_{c l}+I_{a}$ is the sum of surface air layer (insulation of air) $I_{a}$, enclosed air layer $I_{c l}$ as shown Fig. 1, the cross-sectional cylindrical limb of clothed human body.

The human comfort system is the balanced condition between the heat produced by the internal metabolism and losing the heat from body by the means of conduction, convection and radiation. The heat transfer coefficient plays a vital role for maintaining this equilibrium position. The combined heat transfer coefficient $h_{C}$ due to convection $h_{c}$ and radiation $h_{r}$ is given by (Havenith et al., 2002):

$$
h_{C}=F_{c l}\left(h_{c}+h_{r}\right)\left(T_{s k}-T_{\infty}\right)=\frac{T_{c l}-T_{\infty}}{I_{a} / f_{c l}}=\frac{T_{s k}-T_{\infty}}{I_{T}}
$$

The convective heat transfer according to ISO-7933 on the other hand, depends upon the relative air velocity $v_{\text {air }}$ and walking speed given as (Oğulata, 2007; Holmér, 1995; Havenith et al., 2002):

$$
h_{c}=8.7 v_{\text {air }}^{0.6} \text { and } v_{\text {air }}=v_{a}+W_{s}
$$

and:

$$
W_{s}=0.0052(M-58) .
$$

The convective heat exchange $h_{C}$ (Oğulata, 2007) in heat balance equation in Equation 1 is determined by:

$$
h_{C}=h_{c} f_{c l}\left(T_{c l}-T_{\infty}\right)
$$

During last few decades various form of the heat transfer model in biological tissue with protective clothes are tackled by various researchers after (Pennes, 1948). Gurung and Saxena (2010) have used the finite element approach to investigate the one-dimensional transient temperature distribution in human dermal parts with protective clothing at low atmospheric temperature. Havenith (1999) has developed the heat balance wearing protective clothing. Further (Havenith et al., 2002; 2015; Holmér, 1995; Van Hoof et al., 2010; Parsons, 1988; Oğulata, 2007) have developed the model for heat and moisture transfer through clothes by considering various environmental factors and insulation properties.

Though many researchers have played a major role for significant turn into the thermal comfort through protective clothing by taking the heat balance equation and focused on the heat transfer only through clothing, there is still lacking for the study of energy and heat balance in internal human body part and clothing as well. It, therefore, led us to initiate the study of bioheat equation together with these types of clothing insulation properties and air velocity and walking speed.

If one understands the thermal behavior of clothing property as well as human thermo physiological behavior, s/he will be able to determine the thermal comfort. So, this study focuses on both thermal properties of human body and the clothing properties such as insulation of clothes and air, clothing area factor which deals with the heat transfer from skin to environment via clothing and maintain the comfort level.

\section{Mathematical Model}

The study is being carried out on the cylindrical shape of the human body. So, in this study we imply the cylindrical form of one dimensional transient bioheat equation developed by (Pennes, 1948) incorporating the blood perfusion term in heat equation, is given by:

$\rho c \frac{\partial T}{\partial t}=k\left[\frac{1}{r} \frac{\partial}{\partial r}\left(r \frac{\partial T}{\partial r}\right)\right]+W_{b} c_{b}\left(T_{a}-T\right)+q_{m}$

\section{Boundary Conditions}

The temperature at the body core of the living tissue is almost constant (approximately $37^{\circ} \mathrm{C}$ ). So, the equation for boundary condition is given as:

at $r=0, \frac{\partial T}{\partial r}=0$

As skin is covered by the clothes and outside the cloth is exposed to the environment, there is continuous heat flux between the cloth surface and the environment. In this case heat loss from the body to clothes and then clothes to environment is caused by convection, radiation, evaporation and the clothes insulation factors. 
The mixed boundary condition with the heat transfer coefficient in terms of clothing insulation and air insulation is given by:

at $r=R, \quad-k \frac{\partial T}{\partial r}=h_{A}\left(T-T_{\infty}\right)$

The combined heat transfer coefficient $h_{A}$ due to convection and radiation along with clothing area factor and clothing insulation properties $F_{c l}$ in Eq. (2) is given by:

$$
h_{A}=F_{c l}\left(h_{c}+h_{r}\right)
$$

\section{Initial Condition}

The initial condition for the transient boundary value problem is given by:

$T(r, 0)=T_{0}(r)$

\section{Solution of the Model}

While the analytical method is not feasible with non-homogeneous medium, numerical technique will be a strong tool to handle such type of complex problems. So, we perform the Finite Difference (FD) scheme as the numerical method where one dimensional form of cylindrical tissue is divided into $J$ +1 discrete points uniquely specified by spatial indices, $r_{j}$ in the radial direction. The discretization of peripheral human limb where the temperature flow in radial direction is shown in Fig. 2.

In the time discretization, we use backward finite difference scheme. The discrete time step size is denoted by $\Delta t$ and the total time to evaluate the temperature is:

$$
t_{\max }=n \Delta t
$$

The differential equation is approximately expressed in the system of difference equation in finite difference scheme by using Taylor's series expansion. Central difference schemes are used in the interior of the computational domain, while the special boundary stencils are needed near the boundary to make it as accurate as interior stencils. Writing Eq. 3 by using (BTCS) scheme for $j=1,2, \ldots, J-1$ we get:

$$
\begin{aligned}
& \rho c \frac{\partial T}{\partial t}=\frac{\rho c}{\Delta t}\left(T_{j}^{n+1}-T_{j}^{n}\right) \\
& k\left(\frac{\partial^{2} T}{\partial r^{2}}\right)=k\left(\frac{T_{j-1}^{n+1}-2 T_{j}^{n+1}+T_{j+1}^{n+1}}{(\Delta r)^{2}}\right) \\
& k \frac{1}{r}\left(\frac{\partial T}{\partial r}\right)=\frac{k}{r_{j}}\left(\frac{T_{j+1}^{n+1}-T_{j-1}^{n+1}}{2 \Delta r}\right)
\end{aligned}
$$

After plugging these terms into Eq. 3 with:

$$
\begin{aligned}
& D=\frac{k}{\rho c}, \lambda=\frac{D \Delta t}{\Delta r^{2}}, \mu=\frac{D \Delta t}{\Delta r}, \\
& M=\frac{W_{b} c_{b}}{\rho c}, S=\frac{q_{m}}{\rho c} \text { and } F=\Delta t\left(M T_{a}+S\right)
\end{aligned}
$$

the system converts into the form:

$$
\begin{aligned}
& \left(-\lambda+\frac{\mu}{2 r_{j}}\right) T_{j-1}^{n+1}+(1+2 \lambda+M \Delta t) T_{j}^{n+1} \\
& +\left(-\lambda-\frac{\mu}{2 r_{j}}\right) T_{j+1}^{n+1}-F=T_{j}^{n} \quad \text { with } j=1,2, \cdots, J-1
\end{aligned}
$$

Equation 8 is Finite Difference (FD) approximation for interior nodes of the Eq. 3.

\section{FD Scheme at Boundary (Body Core) $r=0$}

The thickness $r$ is me assured from body core towards the skin surface in the cylindrical human body as shown in Fig. 2. At the body core, both $r$ and the heat flux $\frac{\partial T}{\partial r}$, are zero, then $\frac{1}{r}\left(\frac{\partial T}{\partial r}\right)$ approaches to indeterminate form $\frac{0}{0}$ as $r \rightarrow 0$.

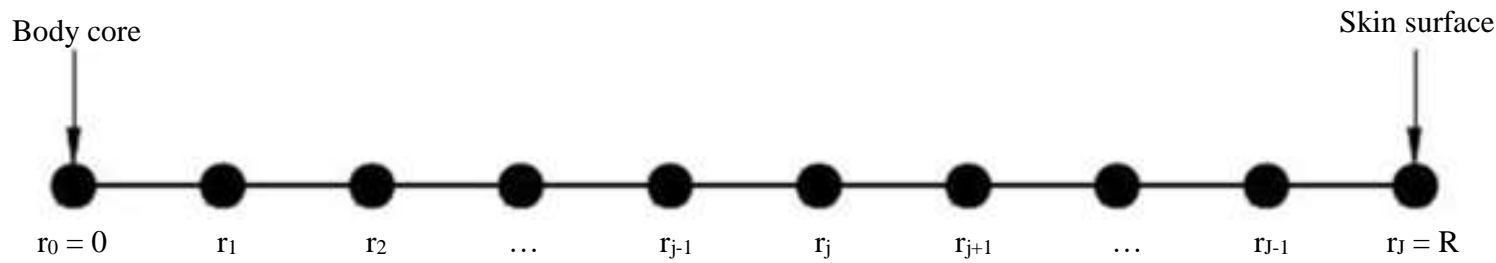

Fig. 2: Discretization in radial direction 
The use of L'Hospital rule, then gives:

$$
\left.\frac{1}{r}\left(\frac{\partial T}{\partial r}\right)\right|_{r=0}=\left.\frac{\left(\frac{\partial}{\partial r}\right)\left(\frac{\partial T}{\partial r}\right)}{\frac{\partial}{\partial r}(r)}\right|_{r=0}=\left.\frac{\partial^{2} T}{\partial r^{2}}\right|_{r=0}
$$

Now Eq. 3 becomes:

$\frac{\partial T}{\partial r}=\frac{2 k}{\rho c}\left(\frac{\partial^{2} T}{\partial r^{2}}\right)+\frac{W_{b} c_{b}}{\rho c}\left(T_{a}-T\right)+\frac{q_{m}}{\rho c}$

FD approximation of Eq. 7 at $r=0$ is:

$-2 \lambda T_{-1}^{n+1}+(1+4 \lambda+M \Delta t) T_{0}^{n+1}-2 \lambda T_{1}^{n+1}-F=T_{0}^{n}$

The FD scheme for $\frac{\partial T}{\partial r}=0$ is:

$T_{-1}^{n+1}=T_{1}^{n+1}$

Using Eq. 11 in Eq. 10, we obtain:

$(1+4 \lambda+M \Delta t) T_{0}^{n+1}-4 \lambda T_{1}^{n+1}-F=T_{0}^{n}$

\section{FD Scheme at Boundary (Skin Surface) $r=J$}

The central difference approximation of Eq. 5 gives:

$T_{J+1}^{n+1}=T_{J-1}^{n+1}-\frac{2 \Delta r h_{A}}{k}\left(T_{J}^{n+1}-T_{\infty}\right)$.

Then FD approximation at $r=J$ of Eq. 7 is:

$-2 \lambda T_{J-1}^{n+1}+\left[(1+2 \lambda+M \Delta t)-\left(-\lambda-\frac{\mu}{2 r_{J}}\right) \frac{2 h_{A} \Delta r}{k}\right] T_{J}^{n+1}$

$+F_{J}-F=T_{J}^{n}$

where, $F_{J}=\frac{2 \Delta r B_{J}}{k}\left(h_{A} T_{\infty}\right)$.

Writing the Eq. 12, 8 and 14 in the matrix equation form:

$A T^{n+1}=T^{n}+B$

were, $T^{n}=\left[\begin{array}{lllll}T_{0}^{n} & T_{1}^{n} & T_{2}^{n} & \cdots & T_{J}^{n}\end{array}\right]^{\prime}$,

$A$ is the corresponding tridiagonal matrix of order $(J+1) \times(J+1), T^{n+1}$ and $B$ are of column vectors of $\operatorname{order}(J+1) \times 1$.

\section{Results and Discussion}

The heat and moisture transfer through clothes for living tissue depends upon the various biological, physiological, environmental as well as clothing properties. In this study the limb of cylindrical human body part is uniformly discretized into the number of small nodes. The heat flow in radial direction occurs from body core towards skin surface.

The role of effective clothing area factor with air insulation can be seen in dry heat transfer and the values of air velocity and walking speed for moisture transfer make changes in temperature of the human body as shown in Fig. 3-7. The values of parameter related to the body part are given in Table 1 .

\section{Effect of Clothing Insulation}

The effect of clothing insulation and air insulation has been observed at the different time steps. The temperature profile with these effects is also compared with the temperature profile in the nude body. The tissue thickness $0.03 \mathrm{~m}$ is taken as the size of space domain. The values of parameters related to internal body parts have been assigned from Table 1 . The solution of the system of Eq. 15 with these parametric values and the additional values (Havenith et al., 2002; 2015). Figure 3 illustrates the graphs for the time dependent temperature profiles with clothing insulation $I_{c l}$ and air insulation $I_{a}$. The parametric values from Table 1 without additional parameters, on the other, are used to obtain the graph of the temperature variation within the nude body in Fig. 4.

Normally surrounding air is cooler than the body's temperature. So, it flows from body core to outer environment as shown in Fig. 2. The cloth keeps the body warm and comfort by trapping a layer of air between person's skin and the fabric. This warmed up layer in Fig. 3 shows the rate of heat transfer from the body representing the temperature profiles at rest and different time steps. When a person removes clothing from her/his body, s/he starts to feel that the layer of trapped air dissipating and reacting to the cooler air around her/him. The rate of heat transfer from body in this situation is higher than that of clothing case. Except rest $(t=0)$ in both case (Clothed and Naked body), the temperature in skin from the body core with certain radial distance is uniform, i.e., steady state and then in Fig. 3 it goes down towards the skin surface and reaches $35.6^{\circ} \mathrm{C}$ in $60 \mathrm{sec}, 35^{\circ} \mathrm{C}$ in $120 \mathrm{sec}$ and $34.5^{\circ} \mathrm{C}$ in $180 \mathrm{sec}$. The results in this case, are the consequences of the insulation of clothes as well as air insulation.

On the other hand, the temperature at nude skin surface are $29^{\circ} \mathrm{C}$ in $60 \mathrm{sec}, 26^{\circ} \mathrm{C}$ in $120 \mathrm{sec}$ and $24^{\circ} \mathrm{C}$ in $180 \mathrm{sec}$ respectively, represented in Fig. 4. Such a result is due to the absence of protective cloth in the body. 


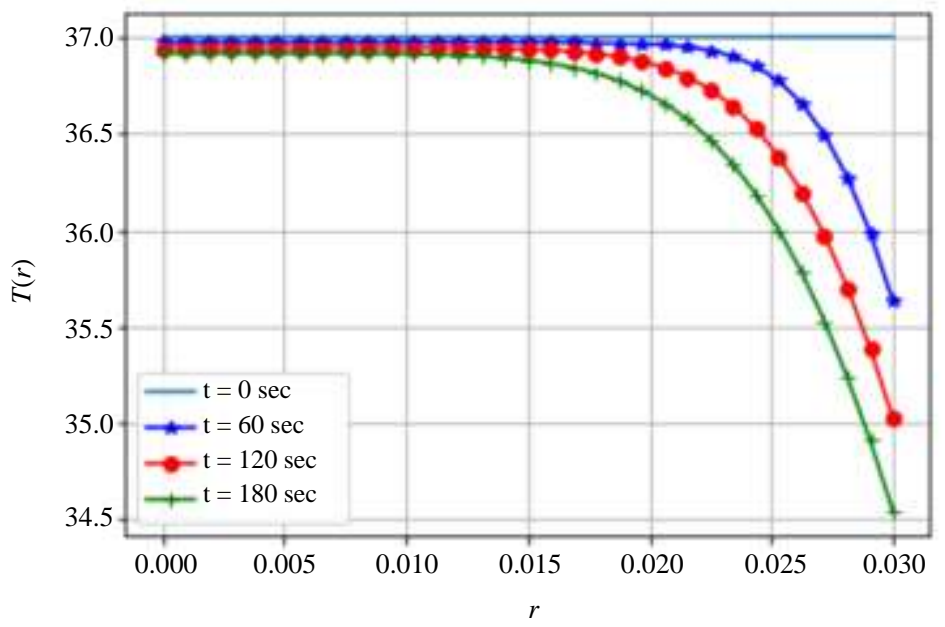

Fig. 3: Variation of skin surface temperature when $I_{c l}=0.172 \mathrm{~m}^{2} .{ }^{\circ} \mathrm{C} / \mathrm{W}, I_{a}=0.0992 \mathrm{~m}^{2} .{ }^{\circ} \mathrm{C} / \mathrm{W}$, vair $=0 \mathrm{~m} / \mathrm{s}$ and $W_{s}=0 \mathrm{~m} / \mathrm{s}$

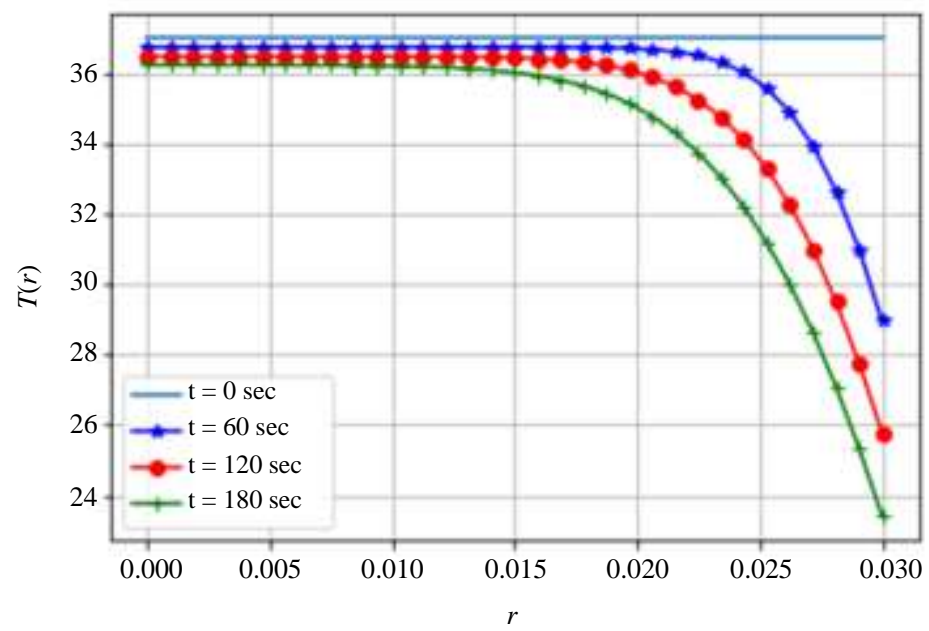

Fig. 4: Radial temperature profile at nude body

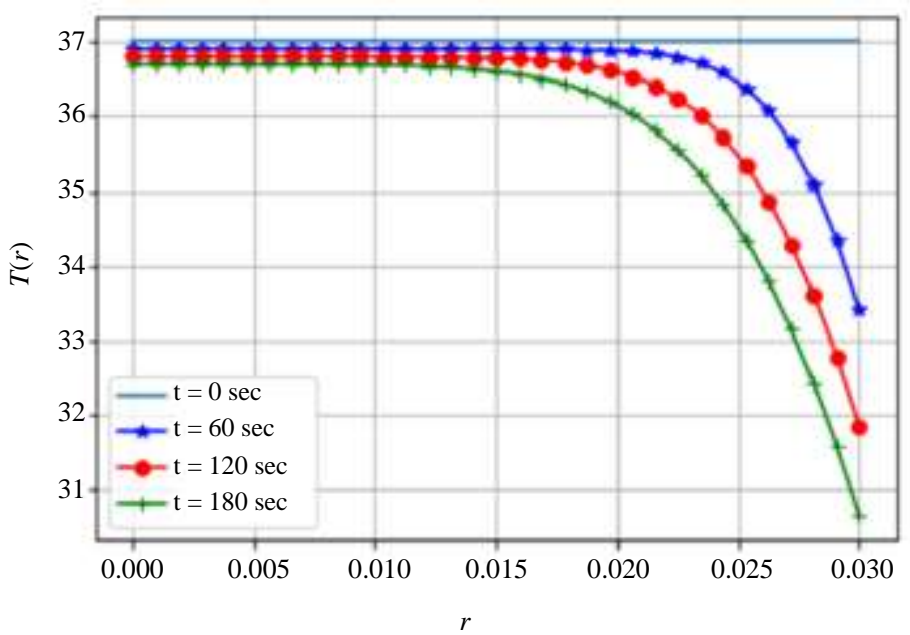

Fig. 5: Variation of skin surface temperature with $I_{c l}=0.172 \mathrm{~m}^{2} .{ }^{\circ} \mathrm{C} / \mathrm{W}, I_{a}=0.0992 \mathrm{~m}^{2} .{ }^{\circ} \mathrm{C} / \mathrm{W}, v_{a}=4.1 \mathrm{~m} / \mathrm{s}$ and $W_{s}=0.42 \mathrm{~m} / \mathrm{s}$ 


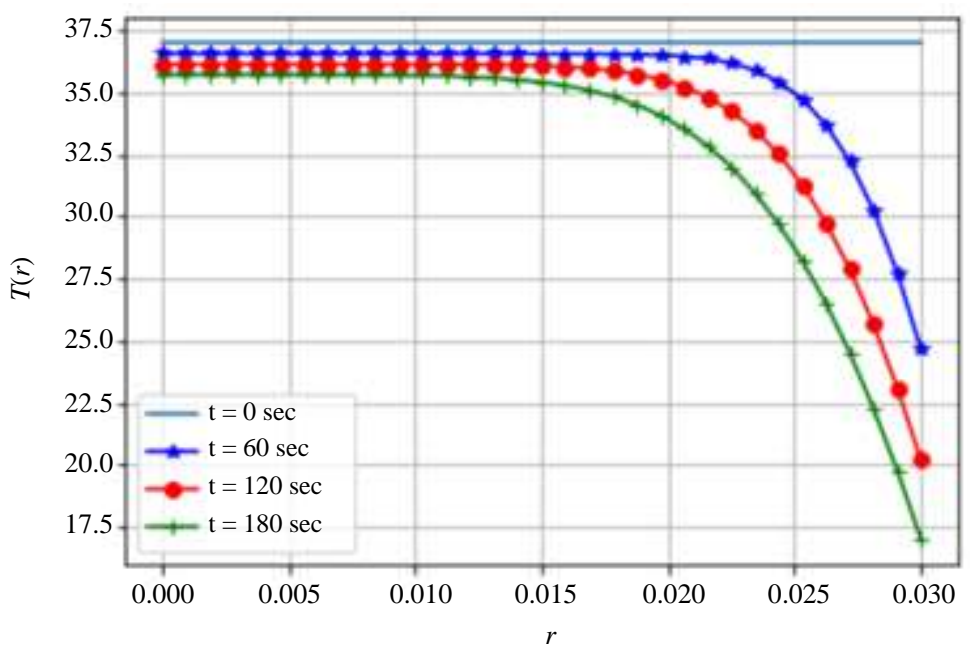

Fig. 6: Variation in temperature with $V_{a}=4.1 \mathrm{~m} / \mathrm{s}$ and $W_{s}=0.42 \mathrm{~m} / \mathrm{s}, I_{c l}=0 \mathrm{~m}^{2} .{ }^{\circ} \mathrm{C} / \mathrm{W}$ and $I_{a}=0 \mathrm{~m}^{2} .{ }^{\circ} \mathrm{C} / \mathrm{W}$

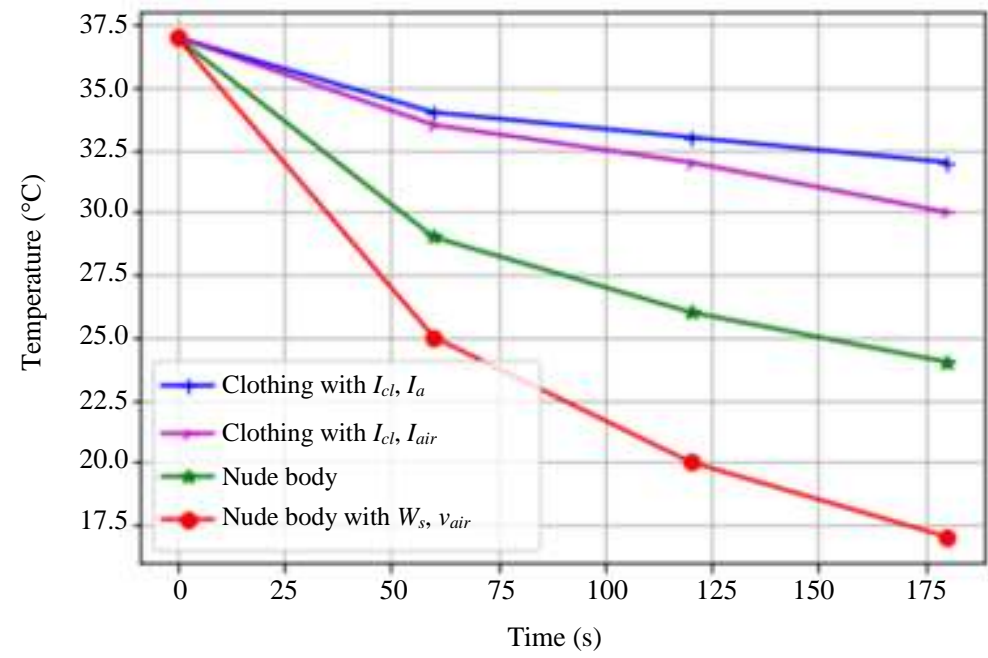

Fig. 7: Temperature profile at skin surface for nude body and clothed body, $R=0.03 \mathrm{~m}$

Table 1: The body's internal and surrounding parametric values (Yue et al., 2004; Luitel, 2017)

\begin{tabular}{llrl}
\hline Parameters & Symbols & Values & Units \\
\hline Thermal conductivities & $k$ & 0.48 & $\mathrm{~W} / \mathrm{m}^{\circ} \mathrm{C}$ \\
Blood specific heat & $c_{b}$ & 3850.00 & $\mathrm{j} / \mathrm{Kg}^{\circ} \mathrm{C}$ \\
Blood density & $\rho_{b}$ & 1000.00 & $\mathrm{~kg} / \mathrm{m}^{3}$ \\
Blood perfusion rate & $w_{b}$ & 3.00 & $\mathrm{~kg} / \mathrm{s}^{3} \mathrm{~m}^{3}$ \\
Metabolism & $q_{m}$ & 1085.00 & $\mathrm{~W} / \mathrm{m}^{3}$ \\
Arterial temperature & $T_{a}$ & 36.98 & ${ }^{\circ} \mathrm{C}$ \\
Tissue thickness & $R$ & 0.03 & $\mathrm{~m}$ \\
Environmental temperature & $T_{\infty}$ & 30.00 & ${ }^{\circ} \mathrm{C}$ \\
Nude body surface area & $A_{b}$ & 1.70 & $\mathrm{~m}^{2}$ \\
\hline
\end{tabular}

\section{Effect of Air Velocity and Walking Speed}

The velocity of wind and person's walking speed have an important role for heat loss from the body. The values have been calculated and assigned from Table 1 along with all additional parametric values related to the air velocity and walking speed and clothing insulation (Havenith et al., 2002; Holmér, 1995) to observe the variation of temperature within the body.

The graphs in Fig. 5 stand for the temperature profile at the different time steps starting from $0 \mathrm{sec}$ up to $180 \mathrm{sec}$. Even though the air velocity and walking 
speed occur, there is only small variation in temperature at the skin surface than that of the temperatures in Fig. 3. This outcome is due to still occurrence of clothing insulation. Figure 6 brings out the effects of wind and walking speed while taking the values of parameters from (Havenith et al., 2002; Holmér, 1995), where no insulation of clothing takes place. These significant variations in temperatures in Fig. 6 at skin surface in different time steps are upshot of the relative velocity of air.

Finally, the graphs in Fig. 7 display the significant variation in temperatures at the skin surface with and without clothing parameters at the time steps 0, 60, 120 and $180 \mathrm{sec}$. From all of these figures, there is no doubt that the clothing insulation helps decrease the rate of heat loss from the body whereas air velocity gives rise to heat loss from the body.

\section{Conclusion}

A cylindrical form of one dimensional Pennes' model for heat transfer through protective clothing is implicitly solved by using the finite difference method. The dry heat transfer and moisture transfer are studied in the microclimate region (between naked and clothed skin environment). Dry heat exchange due to thermal insulation of clothes and the air and moisture transfer due to air velocity with walking speed are compared and analyzed at the different time steps. In this study, the mixed boundary condition incorporating convective heat transfer coefficients with clothing parameters for dry heat exchange and air velocity and walking speed for moisture transfer is added in the in the Pennes' bioheat model. The result shows that the presence of cloth makes major difference in the human thermal comfort level. This paper may helpful for the biomedical researchers as well as environmental designers. They can get benefit from the knowledge of microclimate temperature and accordingly they can design workplace and functional clothing so that people can feel comfort for better performance.

\section{Acknowledgement}

The first author would like to express special thanks to the University Grant Commission, Nepal for PhD Fellowship Award 2019 with the award no. PhD75/76-S\&T-10. The authors are highly grateful to all the anonymous referees and the editor for their valuable comments and suggestions for the improvement of the paper.

\section{Author's Contributions}

Kabita Luitel: Preparation of initial manuscript with numerical solution of transient temperature profile.
Dil Bahadur Gurung: Contribution in developing the model and solution procedure.

Harihar Khanal: Contribution in developing a program and refining the model.

Kedar Nath Uprety: Contribution in developing and refining the model.

\section{Ethics}

There is no any ethical issue regarding to publication of the article. This work is original and has not been submitted and published in any other journal.

\section{References}

Gurung, D. B., \& Saxena, V. P. (2010). Transient temperature distribution in human dermal part with protective layer at low atmospheric temperature. International Journal of Biomathematics, 3(04), 439-451.

Hall, J. E., \& Hall, M. E. (2020). Guyton and Hall textbook of medical physiology e-Book. Elsevier Health Sciences.

Havenith, G. (1999). Heat balance when wearing protective clothing. Annals of occupational Hygiene, 43(5), 289-296.

Havenith, G., Holmér, I., \& Parsons, K. (2002). Personal factors in thermal comfort assessment: clothing properties and metabolic heat production. Energy and buildings, 34(6), 581-591.

Havenith, G., Kuklane, K., Fan, J., Hodder, S., Ouzzahra, Y., Lundgren, K., ... \& Loveday, D. (2015). A database of static clothing thermal insulation and vapor permeability values of non-Western ensembles for use in ASHRAE standard 55, ISO 7730 and ISO 9920. ASHRAE Trans, 121(1), 197-215.

Holmér, I. (1995). Protective clothing and heat stress. Ergonomics, 38(1), 166-182.

Luitel, K. (2017, December). Mathematical model for temperature distribution in cylindrical human body. In 2017 2nd International Conference on Man and Machine Interfacing (MAMI) (pp. 1-5). IEEE.

Luitel, K., Gurung, D. B., \& Uprety, K. N. (2018). Effect of various parameters for temperature distribution in human body: An analytic approach. Advances in Science, Technology and Engineering Systems Journal, Special issue on Recent Advances in Engineering Systems Journal, 3(5), 421-426.

Luitel, K., Khanal, H., \& Uprety, K. N. (2019). Numerical Study of Transient Bio-Heat Transfer Model with Heat Transfer Coefficient and Conduction Effect in Cylindrical Living Tissue. The Nepali Mathematical Sciences Report, 36(1-2), 17-26.

Oğulata, R. T. (2007). The effect of thermal insulation of clothing on human thermal comfort. Fibres \& Textiles in Eastern Europe, 15(2), 61. 
Özişik, M. N., Orlande, H. R., Colaço, M. J., \& Cotta, R. M. (2017). Finite difference methods in heat transfer. CRC press.

Parsons, K. C. (1988). Protective clothing: heat exchange and physiological objectives. Ergonomics, 31(7), 991-1007.

Pennes, H. H. (1948). Analysis of tissue and arterial blood temperatures in the resting human forearm. Journal of applied physiology, 1(2), 93-122.
Van Hoof, J., Mazej, M., \& Hensen, J. L. (2010). Thermal comfort: research and practice. Frontiers in Bioscience, 15(2), 765-788.

Voelker, C., Hoffmann, S., Kornadt, O., Arens, E., Zhang, H., \& Huizenga, C. (2009). Heat and moisture transfer through clothing.

Yue, K., Zhang, X., \& Yu, F. (2004). An analytic solution of one-dimensional steady-state Pennes' bioheat transfer equation in cylindrical coordinates. Journal of thermal Science, 13(3), 255-258. 